\title{
TEMPERATURA DE ARMAZENAMENTO E DESEMPENHO DE SEMENTES HIDRATADAS E OSMOCONDICIONADAS DE PIMENTÃ ${ }^{1}$
}

\author{
SHEILA CRISTINA PRUCOLI POSSE ${ }^{2}$, ROBERTO FERREIRA DA SILVA ${ }^{3}$ e HENRIQUE DUARTE VIEIRA ${ }^{4}$
}

\begin{abstract}
RESUMO- A propagação do pimentão (Capsicum annuum L.) é feita pela semente. Normalmente, tanto a germinação quanto a emergência das plântulas são lentas à temperatura ambiente e mais demorada ainda à baixa temperatura, sendo, portanto necessários estudos que propiciem a germinação mais rápida e uniforme principalmente a baixas temperaturas. Observou-se em trabalho anterior que ao submeter as sementes de pimentão à hidratação em água destilada por 24 e 72 horas e ao condicionamento osmótico com polietileno glicol (PEG 6000) no potencial de -0,5 MPa por 21 dias, foi possível aumentar e acelerar a germinação das sementes a baixa temperatura. Este trabalho foi realizado com o objetivo de avaliar as temperaturas de armazenamento das sementes hidratadas por 24 e 72 horas e condicionadas com PEG 6000 a -0,5 MPa por 21 dias, na preservação da sua viabilidade. As sementes foram tratadas, secas e acondicionadas em embalagem impermeável e armazenadas sob temperaturas de $5^{\circ}$ e $25^{\circ} \mathrm{C}$. Ao término de cada mês de armazenamento, a germinação e emergência das sementes foram avaliadas sob temperaturas de $20^{\circ}$ e $25^{\circ} \mathrm{C}$. Observou-se que as sementes hidratadas por 72 horas não suportaram o armazenamento, devendo estas, serem utilizadas imediatamente após o tratamento. As sementes hidratadas por 24 horas e aquelas osmocondicionadas com PEG quando armazenadas sob temperatura de $5^{\circ} \mathrm{C}$, mantiveram a sua porcentagem de germinação e emergência ao longo dos quatro meses de armazenamento, apresentando os maiores índices de germinação a $20^{\circ} \mathrm{C}$.
\end{abstract}

Termos para indexação: Capsicum annuum L., hidratação, condicionamento osmótico.

\section{INFLUENCE OF STORAGE TEMPERATURE ON THE GERMINATIVE POTENTIAL OF SWEET PEPPER SEEDS SUBMITTED TO HYDRATION AND PRIMING}

\begin{abstract}
The propagation of sweet pepper (Capsicum annuum L.) occurs mainly via seeds. Both germination and emergence of the seedlings are usually slow at ambient temperature and even slower at low temperatures. Therefore it is necessary to study treatments that accelerate these two characteristics. On a preliminary test we submitted sweet pepper seeds to hydration in distiled water for 24 and 72 hours and to osmotic conditioning with polyethylene glicol (PEG 6000) $-0.5 \mathrm{MPa}$ for 21 days at low temperature and the germination of the seeds was increased and accelerated. The objetive of this study was to evaluate the effects of storage temperature and seed dydration for 24 and 72 hours and seed osmotic conditioning with PEG 6000-0.5 MPa for 21 days during 4 months of storage. After treatment the seeds were dried, wrapped in impermeable package and stored under the temperatures of 5 and $25^{\circ} \mathrm{C}$. Monthly the germination and emergence potential of the seeds were determined under the temperatures of 20 and $25^{\circ} \mathrm{C}$. It was observed that the seeds hydrated for 72 hours did not support storage, and its use should be immediately after treatment. Seeds hydrated for 24 hours and those primed with PEG when stored at $5^{\circ} \mathrm{C}$ maintained high germination and emergence percentages throughout the 4 months of storage especially when tested at $20^{\circ} \mathrm{C}$.
\end{abstract}

Index terms: Capsicum annuum L., seeds, hydration, priming.

\footnotetext{
${ }^{1}$ Submetido em 06/06/2003. Aceito para publicação em 15/01/2004

${ }^{2}$ Eng $^{\mathrm{a}}$. Agr ${ }^{\mathrm{a}}$., MS.- Laboratório de Fitotecnia - Campos dos Goytacazes RJ.sheila@uenf.br

${ }^{3}$ Eng $^{\mathrm{o}}$. Agr ${ }^{\circ}$., PhD, Prof. Titular da UENF-Lab. de Fitotecnia - Campos dos Goytacazes-RJ. roberto@uenf.br

${ }^{4}$ Eng $^{\mathrm{o}}$. Agro ${ }^{\circ}$, DS., Prof. da UENF - Lab. de Fitotecnia - Campos dos

Goytacazes-RJ.henrique@uenf.br
}

\section{INTRODUÇÃO}

A propagação da planta de pimentão (Capsicum annuиm L.) se dá por sementes, daí a importância que deve ser dada ao controle da qualidade fisiológica da mesma. $\mathrm{O}$ uso de sementes com alta qualidade é fundamental para se 
obter lavouras uniformes e produtivas (Alvarenga \& Silva, 1984 e Wien,1997).

A germinação de sementes de pimentão e a emergência das plântulas são, normalmente, lentas à temperatura ambiente e mais demorada ainda à baixa temperatura (Pádua et al., 1984 e Wien, 1997). As dificuldades em se obter altas taxas de germinação e emergência de plântulas de pimentão têm estimulado estudos visando identificar tratamentos que superem este problema.

Diferentes procedimentos de "condicionamento osmótico" e hidratação em sementes de pimentão têm mostrado uma considerável redução no tempo de germinação (Wien, 1997). O condicionamento osmótico, "priming", consiste num pré-tratamento no qual as sementes são imersas em solução osmótica sob tempo e temperatura determinados (Anwar et al., 1978), de modo a restringir a quantidade de água absorvida; Assim ocorrem as fases iniciais da germinação (fase I e II), sem ocorrer o estádio de emergência da radícula (fase III) no padrão trifásico (Bewley \& Black, 1994). O tratamento de hidratação consiste na pré-embebição das sementes, antes da semeadura, em água sem a presença de solutos. Neste caso, a quantidade de água absorvida pela semente é controlada pelo período de tempo em que ela permanece em contato com o substrato umedecido (Khan, 1991).

De acordo com Bradford, (1986), para se obterem condições favoráveis ao condicionamento osmótico são importantes a temperatura, a concentração da solução (potencial osmótico), o período de duração do tratamento, o método e o período de secagem após o tratamento. Outros fatores que afetam o sucesso do condicionamento osmótico são a espécie, a cultivar e, dentro da mesma cultivar, o vigor dos lotes de sementes. Fessel et al. (2001), trabalhando com sementes de alface confirmaram as informações de Bradford (1986), verificando que a resposta das sementes ao condicionamento osmótico variou em função do cultivar, do nível de vigor das sementes e do período de embebição das sementes na solução osmótica.

Posse (2000), observou a possibilidade de elevar e acelerar a germinação de sementes de pimentão a baixa temperatura $\left(20^{\circ} \mathrm{C}\right)$ se previamente, forem submetidas ao condicionamento osmótico com polietileno glicol (PEG 6000) no potencial de $-0,5 \mathrm{MPa}$ por 21 dias e à hidratação em água destilada por 24 e 72 horas.

Um ponto em discussão refere-se à manutenção dos efeitos do tratamento durante $\mathrm{o}$ armazenamento das sementes pré-condicionadas. Este é um assunto pouco pesquisado, embora resultados promissores tenham sido obtidos por alguns pesquisadores. Estudos mais detalhados, principalmente quanto à embalagem, ambiente e período de armazenamento apropriado, são necessários para elucidação desses efeitos.

O objetivo deste trabalho foi avaliar se sob duas temperaturas de armazenamento, os efeitos benéficos dos tratamentos de hidratação e de condicionamento osmótico aplicados às sementes de pimentão, se estenderiam por um determinado período de armazenamento.

\section{MATERIAL E MÉTODOS}

O trabalho foi realizado com sementes de pimentão do híbrido Atenas AG-322, fornecidas pela Agroceres, com $6,32 \%$ de umidade inicial. Foram utilizadas para cada tratamento $400 \mathrm{~g}$ de sementes distribuídas em 80 caixas gerbox, ficando, assim, cada caixa gerbox com cinco gramas de sementes. Inicialmente, as sementes foram submetidas à hidratação em água destilada por 24 e 72 horas; ao condicionamento osmótico com polietileno glicol (PEG 6000) a -0,5 MPa por 21 dias e sementes não tratadas corresponderam ao controle. Os tratamentos foram realizados sob temperatura de laboratório, aproximadamente $25^{\circ} \mathrm{C}$. Estes tratamentos foram escolhidos por proporcionar maiores porcentagens de germinação às sementes de pimentão, de acordo com os resultados obtidos por Posse (2001).

As sementes, depois de submetidas aos tratamentos de condicionamento, foram secas em estufa com circulação forçada de ar à temperatura de $32^{\circ} \mathrm{C}$, até que retrocedessem ao teor de umidade inicial, em torno de $6 \%$. Posteriormente, as sementes foram acondicionadas em embalagens impermeáveis, tipo "pouch", e, armazenadas sob as temperaturas de 5 e $25^{\circ} \mathrm{C}$. A temperatura de $5^{\circ} \mathrm{C}$ correspondeu à temperatura de geladeira e a temperatura de $25^{\circ} \mathrm{C}$ foi regulada em uma câmara de germinação tipo BOD. As sementes foram mantidas armazenadas por quatro meses.

Os efeitos dos tratamentos aplicados às sementes foram avaliados ao final de cada mês de armazenamento mediante os testes de germinação em caixas gerbox e de emergência de plântulas em bandejas de isopor, sob duas temperaturas.

Para o teste de germinação foram utilizadas quatro repetições de 50 sementes por tratamento, dispostas em caixas gerbox sobre três folhas de papel germibox umedecidas com água destilada na proporção de 3:1 (ml de água / g de papel). As caixas gerbox foram mantidas em câmara do tipo BOD sob as temperaturas de 20 e $25^{\circ} \mathrm{C}$, sendo as avaliações feitas aos 7 e 14 dias após o inicio do teste.

Para a emergência de plântulas em bandeja foram utilizadas quatro repetições de 20 sementes, colocando-se uma semente por célula da bandeja, contendo o substrato Agromix, a $0,5 \mathrm{~cm}$ de profundidade. Para manter a umidade do substrato próxima a capacidade de campo foram feitas irrigações diárias. As bandejas foram mantidas sob as temperaturas de 20 e $25^{\circ} \mathrm{C}$, com avaliações aos 14 e 21 dias, após o início do teste. 
Adicionalmente, foi obtida a massa da matéria seca da parte aérea por plântula de pimentão que emergiu 21 dias após a semeadura, como avaliação de vigor. Para tanto, 10 plântulas de cada tratamento foram cortadas em sua base, rente à superfície do substrato, colocadas em sacolas de papel previamente identificadas; Após manutenção em estufa com circulação forçada de ar à temperatura de $70^{\circ} \mathrm{C}$, durante 48 horas, seguiram-se as pesagens em balança eletrônica com precisão de $0,0001 \mathrm{~g}$ e os resultados obtidos expressos em mg.plântula ${ }^{-1}$.

$\mathrm{O}$ delineamento experimental utilizado foi $\mathrm{O}$ inteiramente casualizado e os efeitos da temperatura de armazenamento sobre as sementes de pimentão previamente condicionadas por diferentes métodos foram analisados mediante regressão polinomial. Nos casos em que a regressão polinomial ajustada aos dados apresentaram valores negativos para os dados de germinação, emergência de plântulas e massa da matéria seca da parte aérea da plântula, optou-se pela apresentação dos dados originais.

\section{RESULTADOS E DISCUSSÃO}

A germinação das sementes de pimentão osmocondicionadas com PEG 6000 sob as temperaturas de 20 e $25^{\circ} \mathrm{C}$, armazenadas a $5^{\circ} \mathrm{C}$ permaneceu constante durante os períodos de armazenamento (Figura 1-a e Figura 1-b), embora sob $25^{\circ} \mathrm{C}$ os valores foram inferiores ao controle. Entretanto, quando as sementes tratadas com PEG foram submetidas à temperatura de armazenamento de $25^{\circ} \mathrm{C}$, houve uma diminuição da porcentagem de germinação sob a temperatura de $20^{\circ} \mathrm{C}$ (Figura 2-a), a partir do início das avaliações, até o período de quatro meses de armazenamento. Verificou-se um decréscimo progressivo na germinação sob $25^{\circ} \mathrm{C}$, até o período de quarto meses, quando então, a germinação alcançou os menores valores (Figura 2-b). Estes resultados são típicos da perda de vigor das sementes, como pode ser evidenciado pelos valores da massa da matéria seca das plântulas (Figura 3-a e Figura 3b). Resultado semelhante também foi observado para sementes tratadas com PEG 6000 e armazenadas a $25^{\circ} \mathrm{C}$, colocadas para germinar tanto a 20 quanto a $25^{\circ} \mathrm{C}$, quando a emergência das plântulas de pimentão foi decrescente ao longo do período de armazenamento (Figura 4-a e Figura 4b). Portanto, a temperatura de $5^{\circ} \mathrm{C}$ seria a recomendada para armazenar as sementes tratadas com PEG 6000.

Estes resultados corroboram parcialmente com os de Ali et al. (1990) que, após submeterem sementes de cebola e de tomate ao condicionamento osmótico em solução de PEG 8000, verificaram, durante o período de armazenamento de 28 dias a $5^{\circ} \mathrm{C}$, preservação da viabilidade das sementes de cebola e perdas das vantagens do tratamento para as sementes de tomate; resultados estes que discordam dos obtidos por Alvorado \& Bradford (1988) que armazenaram sementes de tomate osmocondicionadas em temperatura igual ou inferior a $20^{\circ} \mathrm{C}$, mantendo a sua viabilidade por cerca de 18 meses, sem prejudicar as vantagens propiciadas pelo tratamento.
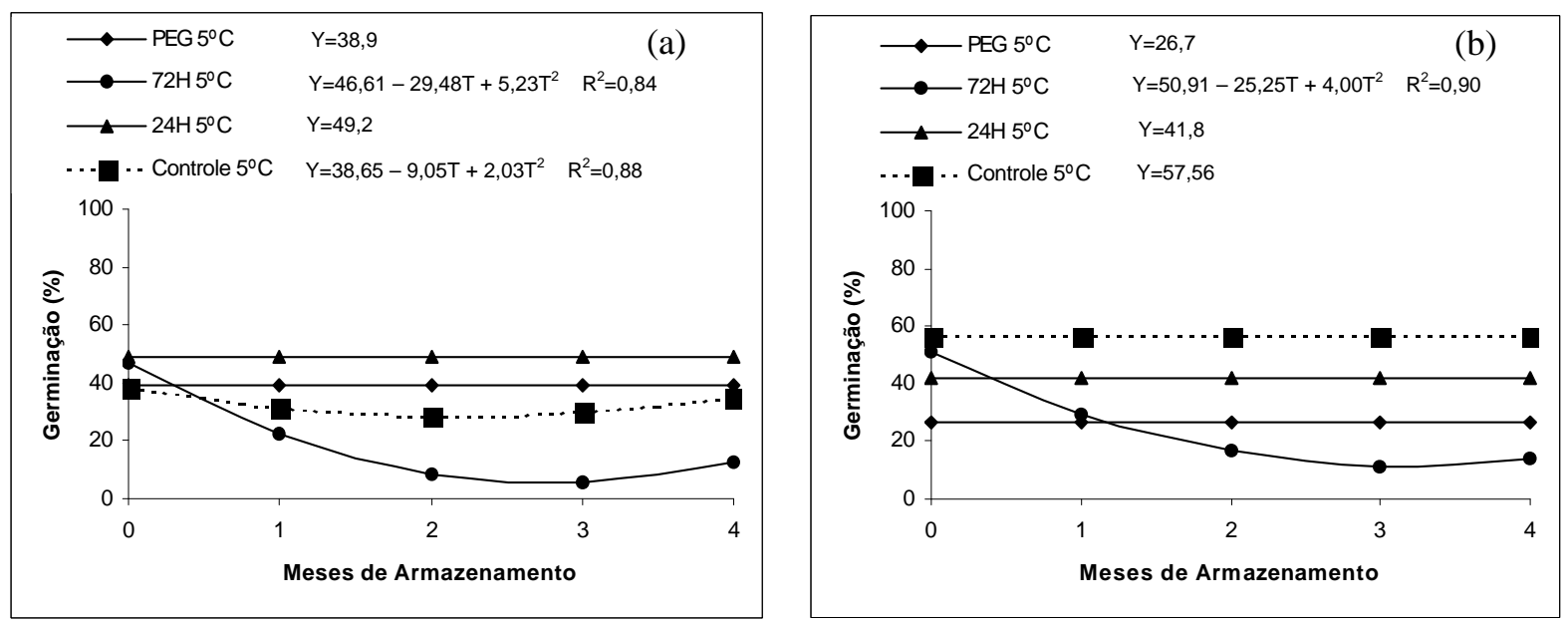

FIGURA 1. Estimativa da germinação à $20^{\circ} \mathrm{C}$ (a) e $25^{\circ} \mathrm{C}$ (b) de sementes de pimentão submetidas a diferentes métodos de condicionamento e armazenadas à $5^{\circ} \mathrm{C}$. 

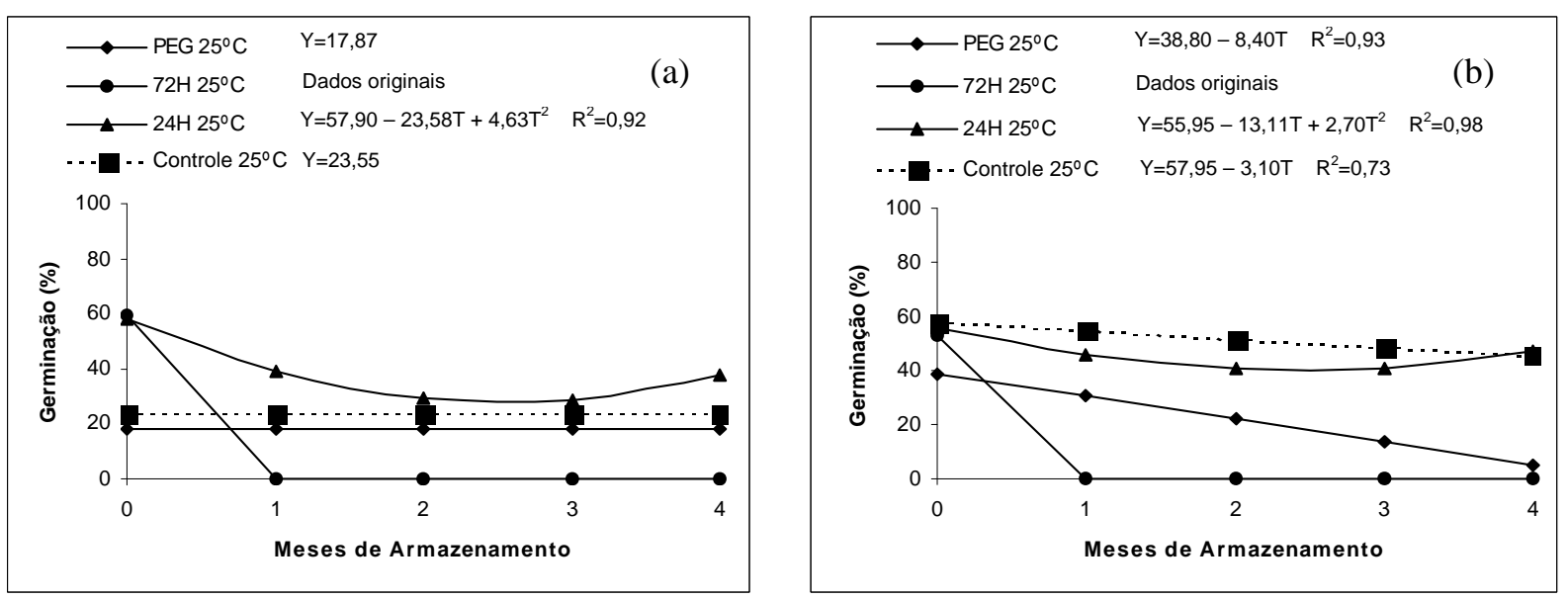

FIGURA 2. Estimativa da germinação à $20^{\circ} \mathrm{C}$ (a) e $25^{\circ} \mathrm{C}$ (b) de sementes de pimentão submetidas a diferentes métodos de condicionamento e armazenadas à $25^{\circ} \mathrm{C}$.

As sementes de pimentão hidratadas em água por 72 horas e armazenadas à $25^{\circ} \mathrm{C}$, não toleraram o armazenamento, não se verificando germinação e emergência de plântulas após o primeiro mês de armazenamento, tanto a 20 como a $25^{\circ} \mathrm{C}$ (Figura 2-a, Figura 2-b, Figura 4-a e Figura 4-b). No entanto, sob a temperatura de $5^{\circ} \mathrm{C}$, as sementes de pimentão apresentaram uma curva evidenciando progressivo decréscimo na porcentagem de germinação ao longo do período de armazenamento (Figura 1-a e Figura 1-b) bem como na porcentagem de emergência das plântulas (Figura 5-a e Figura 3-b), apesar dos valores do vigor, atribuídos a massa da matéria seca das plântulas não indicarem esta perda de vigor ao longo dos períodos de armazenamento (Figura 6-a e Figura 5-b).

Utilizando a temperatura de armazenamento de $5^{\circ} \mathrm{C}$, Passam et al. (1997), conseguiram manter a germinação das sementes de pimentão por 68 meses, o que não aconteceu quando utilizaram a temperatura de $25^{\circ} \mathrm{C}$ de armazenamento, que resultou em baixa germinação e emergência, em condições de laboratório. Estes autores observaram ainda que a deterioração das sementes de pimentão durante um prolongado período de armazenamento difere entre cultivares, sendo influenciada pela temperatura de armazenamento e condições de manejo da cultura.

Os benefícios proporcionados à germinação pela hidratação por 72 horas das sementes de pimentão, apesar de não terem sido verificadas após o armazenamento, mostraram-se eficazes quando as sementes foram semeadas imediatamente após serem hidratadas, tendo sido superior ao seu respectivo controle, notadamente à temperatura de $20^{\circ} \mathrm{C}$ (Figura 1-a e Figura 2-a). No entanto quando a germinação foi avaliada a $25^{\circ} \mathrm{C}$ a hidratação foi ineficaz em melhorar o desempenho das sementes de pimentão (Figura 1-b e Figura 2-b).
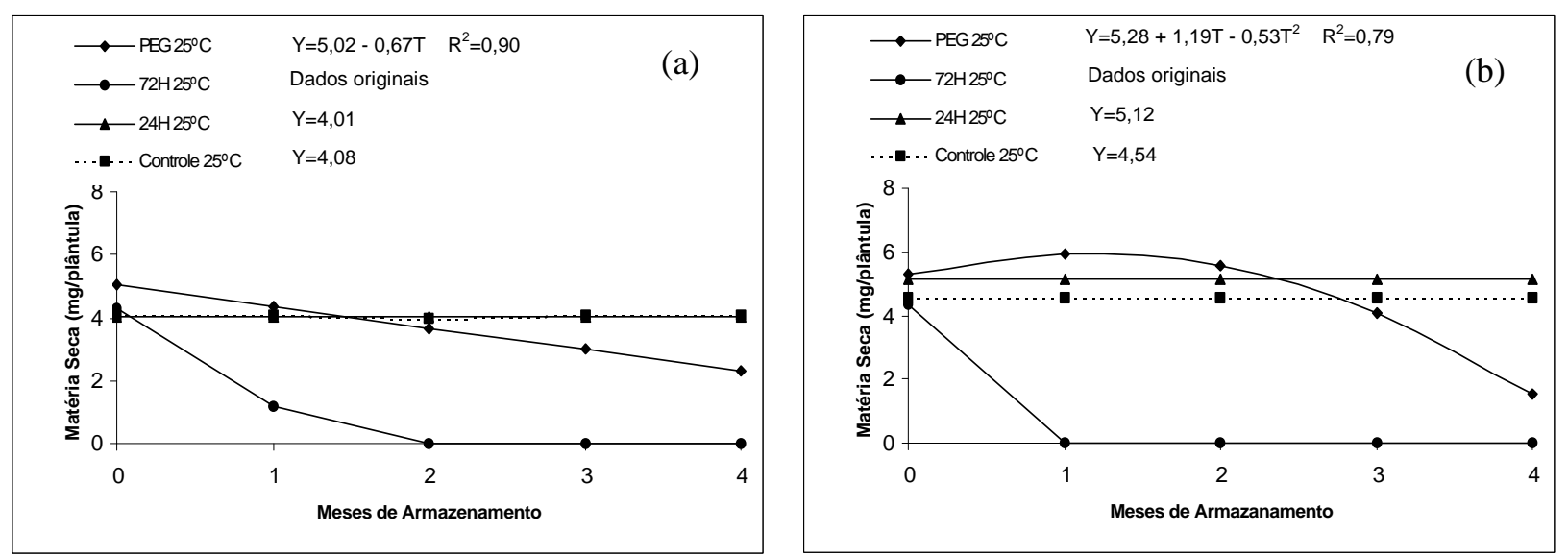

FIGURA 3. Estimativa da massa de matéria seca por plântulas, emergidas em bandejas de isopor à $20^{\circ} \mathrm{C}$ (a) e $25^{\circ} \mathrm{C}$ (b) de sementes de pimentão submetidas a diferentes métodos de condicionamento e armazenadas à $25^{\circ} \mathrm{C}$. 

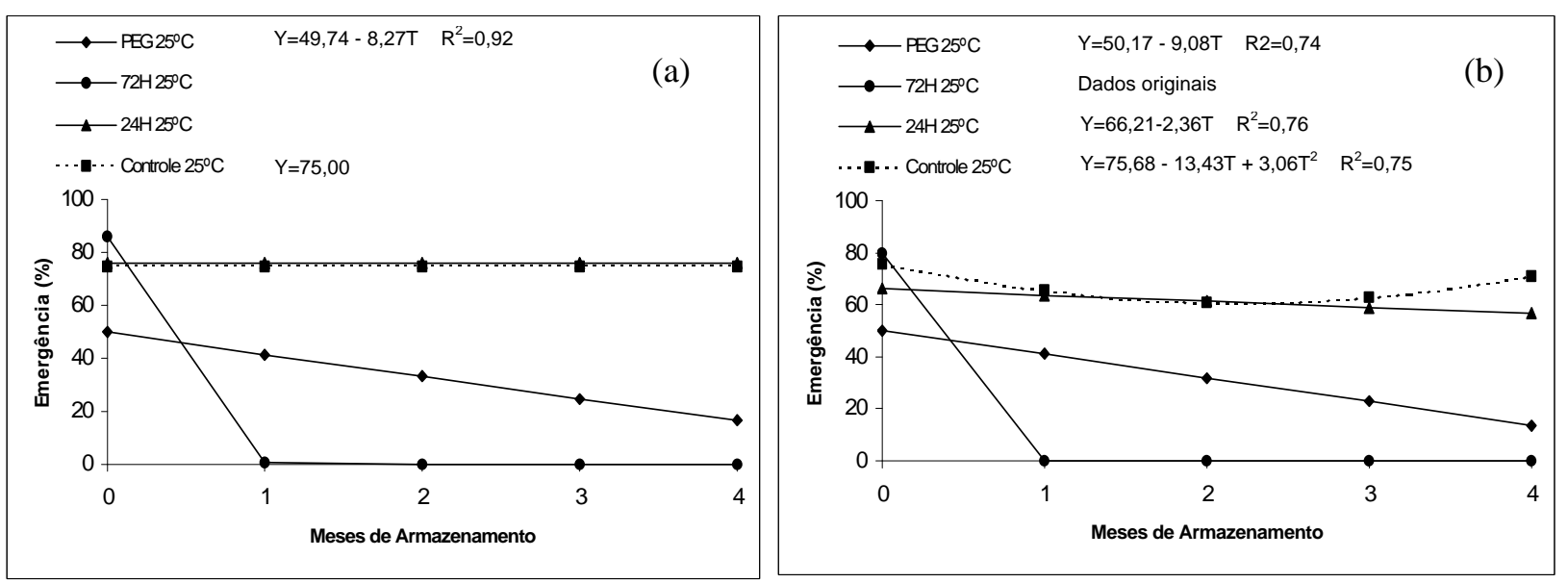

FIGURA 4. Estimativa da emergência à $20^{\circ} \mathrm{C}$ (a) e $25^{\circ} \mathrm{C}$ (b) de sementes de pimentão submetidas a diferentes métodos de condicionamento e armazenadas à $25^{\circ} \mathrm{C}$.
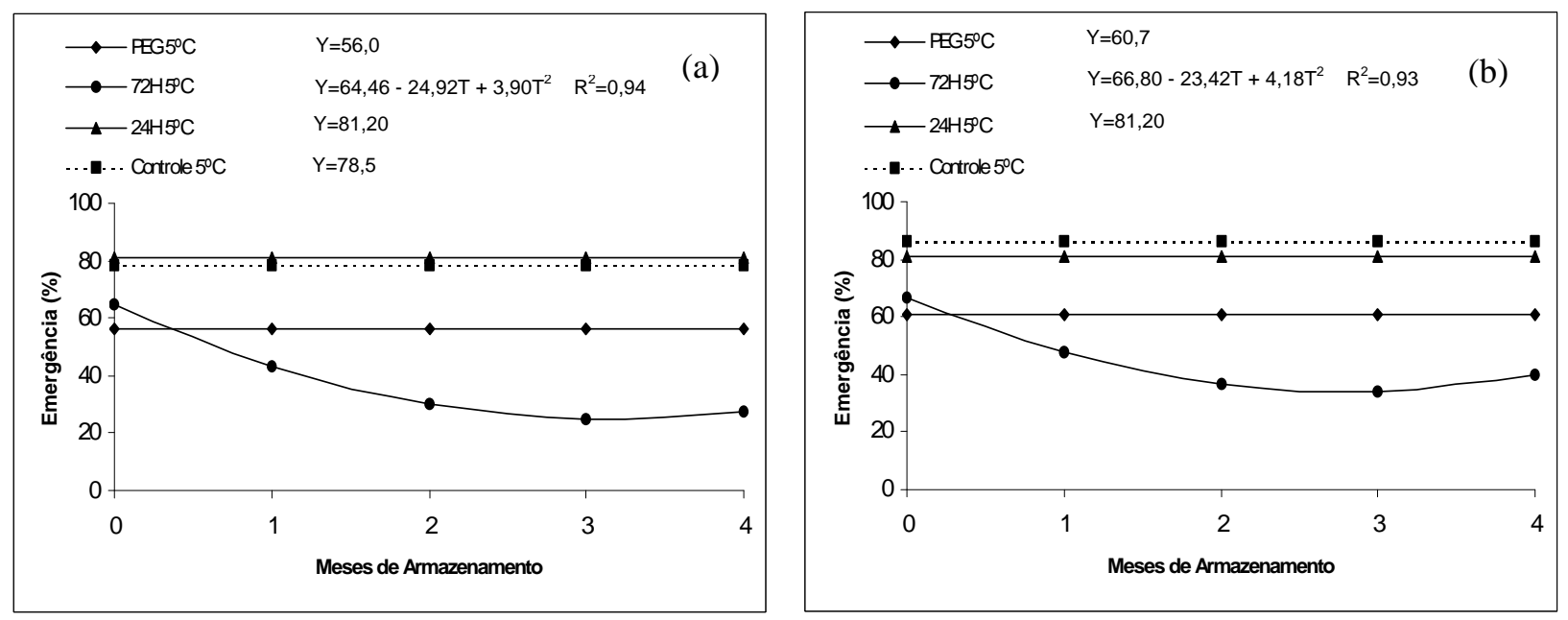

FIGURA 5. Estimativa da emergência à $20^{\circ} \mathrm{C}$ (a) e $25^{\circ} \mathrm{C}$ (b) de sementes de pimentão submetidas a diferentes métodos de condicionamento e armazenadas à $5^{\circ} \mathrm{C}$.
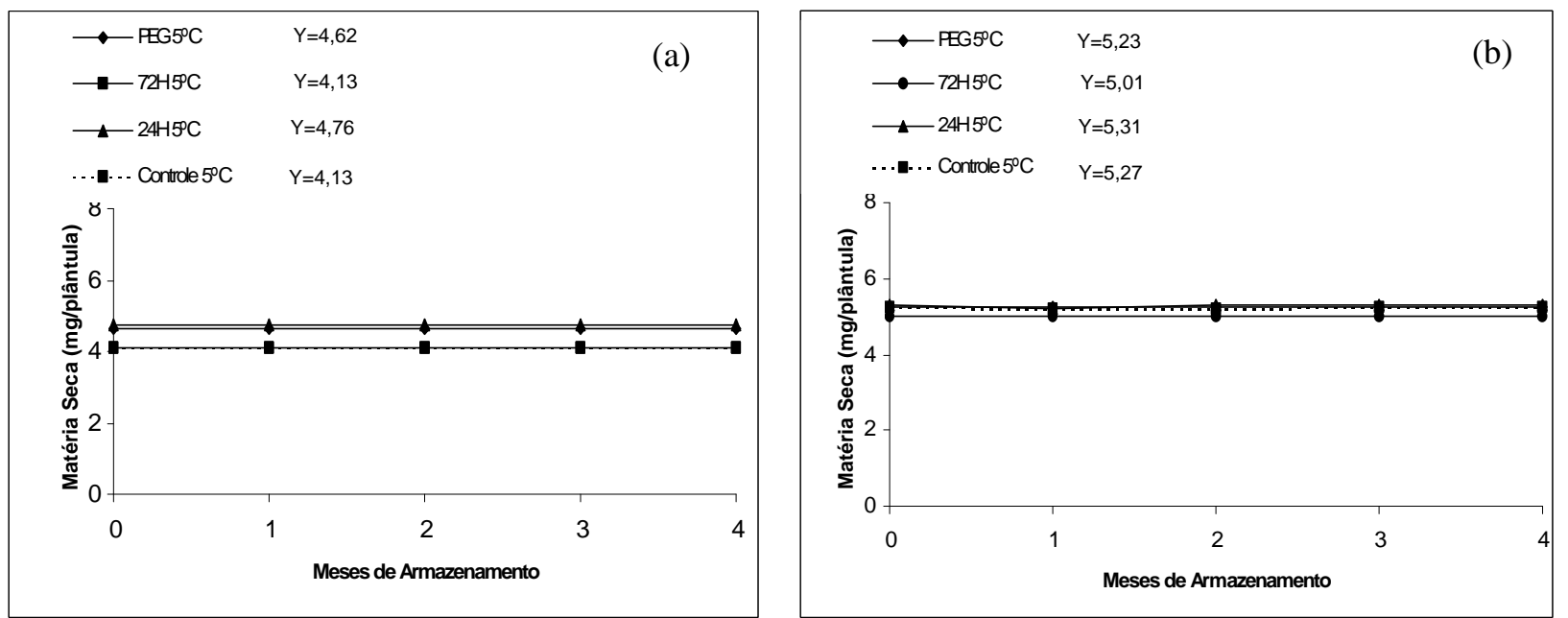

FIGURA 6. Estimativa da massa de matéria seca por plântulas, emergidas em bandejas de isopor à $20^{\circ} \mathrm{C}$ (a) e $25^{\circ} \mathrm{C}$ (b) de sementes de pimentão submetidas a diferentes métodos de condicionamento e armazenadas à $5^{\circ} \mathrm{C}$. 
Resultados semelhantes foram obtidos por Tarquis \& Bradford (1992), com sementes de alface que quando submetidas a extensos períodos de hidratação tiveram a taxa de germinação aumentada, embora tivessem apresentado redução no seu período de armazenamento.

Nas sementes de pimentão hidratadas em água por 24 horas e armazenadas a $5^{\circ} \mathrm{C}$, a porcentagem de germinação foi mantida durante todo o período de armazenamento (Figura 1-a e Figura 1-b), alcançando germinação superior ao seu respectivo controle, principalmente, quando colocadas para germinar a $20^{\circ} \mathrm{C}$ (Figura 1-a e Figura 2-a), o que não foi verificado quando as sementes foram colocadas para germinar a $25^{\circ} \mathrm{C}$ (Figura 1-b e Figura 2-b). Pode-se observar ainda, que ao armazenar as sementes hidratadas por 24 horas sob temperatura de $25^{\circ} \mathrm{C}$, ocorreu um decréscimo na porcentagem de germinação logo após o primeiro mês de armazenamento (Figura 2-a e Figura 2-b). Apesar do armazenamento das sementes a temperatura de $25^{\circ} \mathrm{C}$ ter sido prejudicial a germinação das sementes, não foi verificada perda do vigor, de acordo com os dados da massa da matéria seca das plântulas (Figura 3-a e Figura 3-b).

\section{CONCLUSÕES}

A hidratação das sementes por 72 horas propiciou aumento na germinação apenas para as sementes recém tratadas .

As sementes de pimentão hidratadas por 72 horas não toleraram o armazenamento tanto a 5 quanto a $25^{\circ} \mathrm{C}$.

As sementes hidratadas por 24 horas e osmocondicionadas com PEG, armazenadas a $5^{\circ} \mathrm{C}$ tiveram a sua viabilidade preservada, quando submetidas à germinação a $20^{\circ} \mathrm{C}$.

Não houve efeito dos tratamentos de hidratação por 24 e 72 horas e PEG, quando as sementes foram submetidas à germinação a $25^{\circ} \mathrm{C}$.

\section{AGRADECIMENTOS}

Os autores agradecem a FAPERJ pelo financiamento do projeto.

\section{REFERÊNCIAS}

ALI, A.; SOUZA, M.V.; HAMILL, A.S. Osmoconditioning of tomato and onion seeds. Scientia Horticultural, Athens, v.43. p.213-224. 1990.

ALVARENGA, E.M. ; SILVA, R.F. Produção de sementes de pimentão e pimenta. Informe Agropecuário, Belo Horizonte, v.10, n.13, p.68-70, 1984.
ALVORADO, A.D. ; BRADFORD, K.J. Priming and storage of tomato (Lycopersicon lycopersicum) seeds. I Effects of storage temperature on germination rate and viability. Seed Science and Technology, Zürich, v.16, n.1, p.601-612, 1988

ANWAR, A.K.; KAR-LING T.; KNYPL, J.S.; BORKONSKA, B. ; LOY, E.P. Osmotic conditioning of seed: physiological and biochemical changes. Acta Horticulturae, Sutton Bonington, v.1, n. 83, p.267-278, 1978.

BEWLEY, J.D.; BLACK, M. Seeds: physiology of development and germination. 2.ed. New York: Plenum Press, 1994. 445p.

BRADFORD, K.J. Manipulation of seed water relations via osmotic priming to improve germination under stres conditions. HortScience, Alexandria, v.21, n.5, p.11051112. 1986.

FESSEL, S.A.; VIEIRA, R.D.; RODRIGUES, T.J.D.; FAGIOLI, M.; PAULA, R.C. Eficiência do condicionamento osmótico em sementes de alface. Revista Brasileira de Sementes, Brasília, v.23, n.1, p. 128-133, 2001.

KHAN, A.A. Preplant physiological seed conditioning. Horticultural Review, Edinburgh, v.13, n.1, p.131-181, 1991.

PÁDUA, J.G.; CASALI V.W.D. ; PINTO, C.M.F. Efeitos climáticos sobre pimentão e pimenta. Informe Agropecuário, Belo Horizonte, v.10, n.13, p.11-13, 1984.

PASSAM, H.C.; LAMBROPOULOS, E. ; KHAH, E.M. Pepper seed longevity following production under high ambient temperature. Seed Science and Technology, Zürich, v.25, n.2, p.177-185, 1997.

POSSE, S.C.P. Efeitos do condicionamento osmótico e da hidratação na germinação de sementes de pimentão (Capsicum annuum L.). Campos dos Goytacazes. 2000. 67g. Dissertação (Mestrado em Produção Vegetal), Universidade Estadual do Norte Fluminense, 2000.

TARQUIS, A.M.; BRADFORD, K.J. Prehydration and priming treatments that advance germination also increase the rate of deterioration of lettuce seeds. Journal of Experiment al Botany, Oxford, v.43, n.248, p.307-317, 1992.

WIEN, H.C. The physiology of vegetable crops. In: WIEN, H.C. Peppers. New York: Cab International, 1997. p.259293.

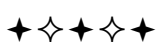

